\title{
Research on the New Trends and Countermeasures of Human Resource Management under the "Internet +" Era
}

\author{
Lin Song \\ Yunnan economic Trade and Foreign Affairs College, Kunming, Yunnan, 650114, China
}

Keywords: Internet +, Human Resource Management, Intelligent

\begin{abstract}
The rapid development of the Internet has brought great changes to the society. In the process of constant change, Internet has also continuously moved toward the direction of "Internet +". This progress has also brought about earth-shaking changes in the management of human resources. In the management of human resources, the management method under the "Internet +" era is more modern and intelligent, using a variety of modern equipment to promote rapid and efficient communication between various departments of the enterprise, helping enterprises to work efficiently, for the progress and development of the enterprise, and inject the driving force. Therefore, based on this background of the times, this paper analyzes the new trends of human resource management, and discusses the countermeasures of human resource management in such an era to improve the quality and effectiveness of enterprise human resource management.
\end{abstract}

\section{Introduction}

The Internet has continued to develop, and communication and communication between people has begun to undergo earth-shaking changes. The Internet has not only brought people closer, but also improved communication efficiency between people. Changes in the way of communication have led to dramatic changes in social form, socio-economics, and social culture. In particular, the emergence of "Internet + " has promoted the development of big data and e-commerce, and the spatial form has undergone tremendous changes. In the human resource management of enterprises, "Internet +" has played a big role in it. It has changed the previous single communication method and a single human resource management and control method, and adhered to the principle of cross-border cooperation and innovation creation under the Internet era, and provided impetus for the improvement of human resource management effect.

\section{Overview of "Internet +"}

In the Third National Congress of the National People's Congress, Premier Li Keqiang put forward the concept of "Internet +", a concept not only for computer technology, but also a form of social economy. "Internet +" has seven characteristics: cross-border integration, innovation-driven, reshaping structure, respect for humanity, open ecology, linking everything, and the legal economy. These seven characteristics guide the modernization trend of social development. After the concept of "Internet +" was put forward, China's social economy has entered a new level of development. It not only connects all walks of life, but also enhances the economic self-innovation ability, which is produced in all production factors. Greatly, the traditional economic landscape has changed. In today's society, if enterprises want to develop for a long time, they must rely on "Internet +" to bring innovation and help enterprises to conform to the form of modern social and economic development in order to survive in the modern social economy.

\section{The Impact of "Internet +" on Enterprise Human Resources Management}

Fully understanding and understanding the concept of human resource management can more clearly analyze the development direction of human resource management in the era of "Internet +", and clarify the added benefits that human resource management can bring on this basis. Our 
definition of human resources is mainly the sum of the labor capacity of all workers and those with certain working ability within a certain scope of work. Continuously doing a good job in human resource management is also the basis for promoting social and economic development. In an enterprise, human resource management is mainly divided into modules such as recruitment, training, assessment and incentives. By combining these four modules, the enthusiasm of employees is promoted and the highest economic value is brought to the enterprise. People are the foundation of an enterprise. If you want to develop stably and continuously, you must do a good job in the management of human resources within the company to ensure that employees can adapt to the adjustment and development of the company. With the advent of the Internet era, the management of human resources has begun to undergo earth-shaking changes. As the core value of enterprises begins to change and change, the core of human resources management has also changed. In this change, the value chain has gradually become the core content of human resource management. From the system with labor and land as the main value, it gradually changes to the value of modern social economy with knowledge and capital. The distribution of value has also begun to change, and the requirements for distribution, the distribution method and the allocation criteria have become the core issues in modern human resource management. solve these problems,. It can prompt human resource management to catch up with the pace of "Internet +" development.

Human resources management is more frequent on the basis of "Internet +", and through the Internet knowledge and technology, select more talents for enterprises. In the context of "Internet +", we can collect talent data, analyze the collected data, and select the talents that best meet the requirements of the company with certain criteria. In addition, using the Internet, the human resources management department can also adjust the positions, salary and training of personnel according to the change of the company's ratio, and can confirm the talents that the position is suitable through accurate data analysis. At the same time, the employees can be accurately positioned. Employees can also use the Internet to find the right job to ensure that the demand matches the demand. The emergence of "Internet + " has provided convenience for the human resources management department in the management of company personnel. The intelligent management method not only improves the efficiency of human resource management, but also improves the quality of human resource management.

In the process of human resource management, "Internet+" promotes closer communication between employees and more frequent communication. This communication enhances the ability of employees to collaborate and greatly weakens the bureaucratic characteristics that may exist in the enterprise. The way human resources are managed. In addition, "Internet + " can also achieve a cross-regional human resource management model, which not only helps companies reduce the barriers to expansion, but also becomes a supporting force for enterprise expansion. Therefore, in this case, the human resource management of the enterprise truly realizes the management mode without geographical restrictions, and the management mode that does not require leadership is gradually formed. For employees, it is possible to quickly communicate and strengthen colleagues. Therefore, the human resource management model based on the Internet has become more and more a tool to meet the development requirements of modern enterprises.

\section{The New Trend of Human Resources Management under the "Internet +" Era}

The traditional human resource management model is a pyramid model. From top to bottom management, the top leaders control the size of the entire human resources management and play a controlling role in the entire group. The main reason is that in the traditional enterprise development, the development and planning of the whole enterprise is arranged and managed by the managers, so the work of human resource management needs to be mastered by the senior leaders, so as to ensure that the development of human resources can be satisfied. However, this kind of operation makes the value of the enterprise difficult to be reflected, so the development of the enterprise has been limited. Under the influence of "Internet +", human resource management can connect each department and connect each team. Therefore, in the management of the enterprise, the team is the most important manager, and the flat management mode makes the human resources The 
management style has undergone tremendous changes, and companies have changed. It can be seen that under the "Internet +" era, the traditional management model has no way to meet the needs of modern enterprise development and affect the progress and development of enterprises. Therefore, in this context, the managerial role of human resource management needs to change. From a strategic perspective, to understand the development changes brought by "Internet+" to enterprises, enterprise managers must change themselves from leaders to partners.

The traditional human resource management method is centralized and controlled. Therefore, in the era of "Internet +", this centralized method needs to develop in the direction of intelligence and information. Human resources management in the context of "Internet + " is free to make statements so that companies that match their personal values can be selected to achieve a fit between the two. This approach can not only help companies develop more stably, but also help individuals improve their The value level of the self. Therefore, in modern enterprise management, human resource management has become a very important task. Not only does the management object be a manager, but also the management object becomes a participant or even an implementer of the management work. In addition, when the company chooses employees, it needs to judge the ability and judgment of the employees. According to the ability of a large number of employees, the training mechanism of the enterprise is adjusted, and the salary of the employees in the enterprise is required. The salary and benefits are adjusted. In this way, we can ensure that enterprises can constantly adapt to the development trend of the society, promote the personal progress of employees under the premise of ensuring the development of the enterprise, and rely on the progress of employees to lay a better foundation for the development of the enterprise, thus forming a virtuous circle. Guarantee the stability of the enterprise and obtain greater benefits and value.

\section{The Countermeasures of Human Resources Management under the Era of "Internet +"}

Under the background of "Internet +", if enterprises want to develop, they must conform to the development direction of the times. Therefore, the human resources management methods of enterprises must be changed, abandon the traditional human resource management dross, and reform the management concept. The management method is upgraded, and the management talents are continuously cultivated. In the new human resource management system, "Internet + " is used as the latest management mode to form a systematic, intelligent and informatized human resource management system, and all aspects of the human resources management system are adjusted and revised. When modifying the human resources management system, we must first change the human resource management thinking and improve the management methods and means based on the "Internet + " thinking. Management thinking has been achieved, combined with a reasonable management system, can guarantee the quality and effectiveness of human resource management,

With Internet thinking and a sound human resources management system, we need to adjust the specific organizational structure, modify the deficiencies in the traditional human resources management system, and retain the available. In the era of "Internet +", the work of human resource management is simpler and faster, so enterprises can quickly grasp the situation of social talents, and effectively manage and analyze these situations, and constantly improve the enterprises according to market demand. A stable organizational structure is the basis for ensuring the development and progress of the company. Establish a reasonable organizational structure, based on the actual situation, based on the needs of the self can not be human, and adopt a humanized and rational way to build a reasonable organizational system, thereby stabilizing the foundation of the entire enterprise and enhancing the internal literacy of the enterprise.

In the process of development, what enterprises cannot lack is talents. Talents are an important element of enterprise management, production and development. As a management department of human resources, how to retain corporate talents has become an urgent problem to be solved in a modern fast-paced society. Therefore, in the era of "Internet +", when we establish a human resources management mechanism, we must be people-oriented, respect employees, understand employees, and employees are the core and main body of company management. In addition, companies need to establish appropriate incentives to improve the quality of human resource 
management. For example, employees' five insurance and one gold and other countries' welfare benefits. Different employees are different in their ability to demonstrate their abilities. Therefore, the incentive mechanism is to meet the needs of different employees for welfare treatment, not only from the perspective of the enterprise, but also from the perspective of employees. It can be combined with the idea of the enterprise to establish a human resource management system under the "Internet +" era that is relatively complete and meets the requirements of enterprise development.

\section{Conclusion}

Enterprises should be people-oriented, and human resource management work as an important task of enterprise management has a huge impact on the survival and development of the company. Therefore, we need to pay attention to human resources management. Especially in the modern era of "Internet +", we must seize the requirements and trends of the development of the times, rationally carry out the reconstruction and adjustment of the system of human resources management according to the characteristics of the development of the times, and actively use the "Internet $+"$ for the work of human resources management. The advantages of the company will ensure that the company can develop rapidly under the perfect human resource management system and meet the requirements of the times to obtain maximum benefits and value.

\section{References}

[1] Zhu Cong. Analysis of the New Trends and Countermeasures of Human Resource Management in the Age of "Internet +"[J].Trade Practice.2018 (09)

[2] Zhang Chundong. Analysis of new trends and measures of human resource management based on "Internet +" [J]. Science and Technology Innovation Guide. 2018 (07)

[3] Li Jinmei. Analysis of the New Trends and Countermeasures of Human Resource Management in the Age of "Internet +"[J].Commercial Economy.2017 (01) 